\title{
Genome-Wide Analysis and the Expression Pattern of the MADS-Box Gene Family in Bletilla striata
}

\author{
Ze-Yuan Mi, Qian Zhao, Chan Lu, Qian Zhang, Lin Li, Shuai Liu, Shi-Qiang Wang $\mathbb{C}^{\mathbb{D}}$, Zhe-Zhi Wang * \\ and Jun-Feng Niu *
}

Citation: Mi, Z.-Y.; Zhao, Q.; Lu, C.; Zhang, Q.; Li, L.; Liu, S.; Wang, S.-Q.; Wang, Z.-Z.; Niu, J.-F. Genome-Wide Analysis and the Expression Pattern of the MADS-Box Gene Family in Bletilla striata. Plants 2021, 10, 2184. https://doi.org/10.3390/

plants10102184

Academic Editor: Yong-Gu Cho

Received: 2 September 2021

Accepted: 10 October 2021

Published: 14 October 2021

Publisher's Note: MDPI stays neutral with regard to jurisdictional claims in published maps and institutional affiliations.

Copyright: (c) 2021 by the authors. Licensee MDPI, Basel, Switzerland. This article is an open access article distributed under the terms and conditions of the Creative Commons Attribution (CC BY) license (https:// creativecommons.org/licenses/by/ $4.0 /)$.
National Engineering Laboratory for Resource Development of Endangered Crude Drugs in Northwest China, Key Laboratory of the Ministry of Education for Medicinal Resources and Natural Pharmaceutical Chemistry, College of Life Sciences, Shaanxi Normal University, Xi'an 710119, China; mizeyuan@snnu.edu.cn (Z.-Y.M.); triumph@snnu.edu.cn (Q.Z.); luchan@snnu.edu.cn (C.L.); zq182568@snnu.edu.cn (Q.Z.); shidalilin@snnu.edu.cn (L.L.); liushuai.28@163.com (S.L.); wsq@snnu.edu.cn (S.-Q.W.)

* Correspondence: zzwang@snnu.edu.cn (Z.-Z.W.); niujunfeng@snnu.edu.cn (J.-F.N.)

\begin{abstract}
Bletilla striata (Thunb. ex A. Murray) Rchb. f., a species of the perennial herb Orchidaceae, has potent anti-inflammatory and antiviral biological activities. MADS-box transcription factors play critical roles in the various developmental processes of plants. Although this gene family has been extensively investigated in many species, it has not been analyzed for B. striata. In total, 45 MADS-box genes were identified from B. striata in this study, which were classified into five subfamilies ( $\mathrm{M} \delta, \mathrm{MIKC}, \mathrm{M} \alpha, \mathrm{M} \beta$, and $\mathrm{M} \gamma$ ). Meanwhile, the highly correlated protein domains, motif compositions, and exon-intron structures of BsMADSs were investigated according to local B. striata databases. Chromosome distribution and synteny analyses revealed that segmental duplication and homologous exchange were the main BsMADSs expansion mechanisms. Further, RT-qPCR analysis revealed that $B S M A D S s$ had different expression patterns in response to various stress treatments. Our results provide a potential theoretical basis for further investigation of the functions of MADS genes during the growth of B. striata.
\end{abstract}

Keywords: Bletilla striata; MADS gene family; expression pattern

\section{Introduction}

MADS-box transcription factors are important regulators that participate in several plant growth processes, seed development, and in response to abiotic stress [1-6]. MADSbox genes have been identified in plants [7], animals [8], and fungi [9], and are well-known in the ABCDE model, which describes their functionality in the determination of floral organs [10,11]. Additionally, MADSs play essential roles in gymnosperms and mosses without flowers [12,13]. The term MADS is an abbreviation consisting of the initials of Saccharomyces cerevisiae transcription factor MCM1 [14], the flower homologous gene AGAMOUS (AG) of Arabidopsis thaliana [15], DEFICIENS (DEF) of Antirrhinum majus [16], and the human serum response factor (SRF) [17].

All MADS-box gene family members contain a DNA-binding domain of $~ 60$ amino acids, known as the MADS-box domain, located at the N-terminal region of the protein [18]. In A. thaliana, the gene family can be sub-divided into two classes based on gene structure: type I ( $\mathrm{M} \alpha, \mathrm{M} \beta, \mathrm{M} \gamma$, and $\mathrm{M} \delta$ ) and type II (MIKC) [19]. This diversity is primarily caused by a gene duplication event [20]. The plant type II genes contain highly conserved MADS domains - of which the K-domain is essential for functional diversity and protein-protein interactions [21]—-while type I MADS-box genes have a relatively simple structure and lack a K-domain. Although the MADS-box genes in type II have been well documented and extensively studied, few reports exist that describe type I MADS-box genes in plants [22-24].

Bletilla striata (Thunb.) Rchb. f. is a perennial medicinal herb of the Orchidaceae family that is extensively distributed across China, Korea, Japan, and Myanmar [25]. According 
to the earliest pharmacopeia of traditional Chinese medicine, Shennong's Materia Medica Classic, B. striata has a long history of treating tuberculosis, whooping cough, hemorrhoids, eye diseases, and more [26]. B. striata also exhibits a range of unique flower shapes with high ornamental value. MADS-box transcription factors are key regulators of flower development, which might improve the quality of B. striata by expediting flowering times.

The development of bioinformatics technology has resulted in more specific plant genomics research, especially concerning the functional screening and verification of genes. Examples of these research findings include: PIN-FORMED (PIN) genes and brassinazoleresistant (BZR) genes have a vital role in Triticum aestivum $\mathrm{L}$. growth and development under various stress conditions $[27,28]$; the KCS gene family in barley shows diverse expression patterns under drought stress [29]; LncRNAs in Capsicum annuum regulate transcription factors by interacting with miRNAs [30]; natural antisense transcripts in Salvia miltiorrhiza potentially regulate the biosynthesis of bioactive compounds [31]; and that AT-hook motif nuclear-localized genes mediate the stress response of soybean [32]. The MADS-box gene family has also been studied in many plants, especially A. thaliana $[7,19,33]$ and rice [1,34,35], as well as orchids such as Erycina pusilla [36] and Phalaenopsis orchid [37]. The identification of MADS-box family genes in orchids can provide useful information for both breeding and flowering. However, there is no in-depth research on MADS-box genes and their roles in B. striata.

In this study, the first genome-wide analysis of $B$. striata was conducted, including its genetic structure, motif compositions, cis-elements, chromosome distribution, and synteny analysis. Based on sequence alignments and phylogenetic tree analyses, we divided the $B s M A D S s$ into five subfamilies. The expression patterns of the BsMADSs revealed that the stress-responsive BsMADS genes responded to various treatments. Our results may provide a better understanding of the origins of gene diversification within each subfamily, and the basis for gene function analysis to elucidate their specific roles in the development of B. striata.

\section{Results}

\subsection{Identification of BsMADS}

A total of 45 presumed MADS proteins were searched from the B. striata protein databases using the BLASTP program with 146 AtMADS (70 M-type MADS and 76 MIKC MADS) proteins as queries. All B. striata MADS proteins (designated BsMADS01 to BsMADS45) were confirmed to contain a single SRF-TF domain by InterProscan and SMART (Supplementary Table S1). The number of BsMADS genes was less than the identified MADS genes in Arabidopsis (146) and rice (75).

The basic features of the BsMADSs were predicted, and the coding sequence (CDS) lengths of 45 BsMADS genes ranged from $438 \mathrm{bp}$ (BsMADS41) to $8612 \mathrm{bp}$ (BsMADS14); thus, the proteins encoded would potentially include from 75 (BsMADS45) to 433 amino acids (BsMADS20). The molecular weight (MW) ranged from 8713.2 to $49280.86 \mathrm{Da}$. The isoelectric point (pI) ranged from 4.66 (BsMADS23) to 10.43 (BsMADS45). The prediction of subcellular localization revealed that all BsMADS proteins resided in the nuclear region (Supplementary Table S2).

\subsection{Analysis of Multiple Sequence Alignments and Cis-Acting Elements}

Multiple sequence alignments were performed based on the conserved SRF-TF domain of BsMADSs (Figure 1). The results revealed some highly conserved amino acids in the SRF-TF domain, including the 15th arginine (R), 21st lysine (K), 25th glutamic acid (E), 26th leucine (L), etc. (Figure 1a), which verified that the domain was a highly conserved DNA-binding/dimerization region [38]. 
a

b

BsMADS01

BsMADS02

BsMADS03

BsMADS04

BsMADS05

BsMADS06

BsMADS07

BsMADS08

BsMADS09

BsMADS10

BsMADS11

BsMADS12

BsMADS13

BsMADS14

BsMADS15

BsMADS16

BsMADS17

BsMADS18

BsMADS19

BsMADS 20

BsMADS 21

BsMADS 22

BsMADS 23

BsMADS24

BsMADS25

BsMADS 26

BsMADS27

BsMADS28

BsMADS29

BsMADS 30

BsMADS 31

BsMADS 32

BsMADS 33

BsMADS 34

BsMADS 35

BsMADS 36

BsMADS 37

BsMADS 38

BsMADS 39

BsMADS40

BsMADS41

BsMADS42

BsMADS43

BsMADS44

BsMADS45

Consensus

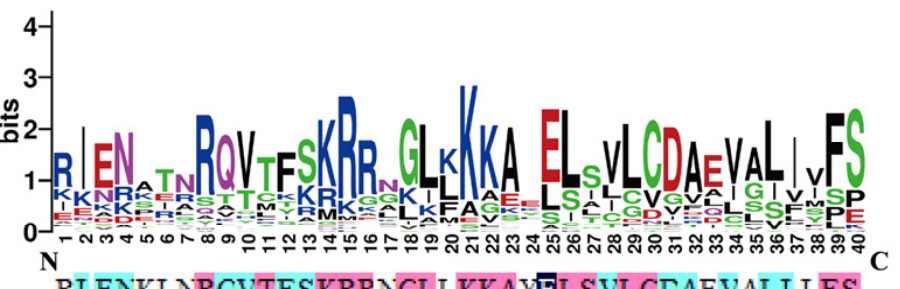

RI ENKI NRCVTFSKRRNGLLKKAYELSVLCCAEVALI I FS

RI EKEENRCVCF SKRRCGLFKKANELCTLCGAEVAI I VFS

RI EKEENRCVCFSKRRCGLFKKANELCTLCGAEVAI I VFS

RI ENPVHRCQVTFCKRRAGLL KKAKEL SVLCDALI VLL.

RI ENKI NRCVTF AKRRNGLL KKAYELSVLCDAEVALI I FS

KI ENPTSRCQVTYSKRRL GI MKKAEEL TVLCDACQVSLI MFS

KI ENPTNRCQVTYSKRRAGI MKKAREI TVLCDAEVSLI MFS

KI NNVTARCVTF SKRRRGLFKKAEELSI LCDAEVGLI VFS

RI ENEEARCVCFSKRRAGLFKKATELSI LCGAEI GI VVFS

. LEKASGRCL TYSKRRVGI TTKAKELSI LCDI LI LLLLFS

KI ENPTNRCVTYSKRRVGI LKKAKEL TVLCLACVVLI MFS

. I TNDATRRATLKKRRRGLLKKASEL SI LCNVSACAVI YS

RI LNTTTRCVAFSKRRNGLLKKAKELAVLCDAEVGVI VFS

RI ENSTNRCVTFSKRRNGI MKKAKEI SVLCDACVSLVI FS

PI KKEEARCVCF SKRRNGLFKKASELSTLCGAEI CI VVFS

RI ENKI NRCVTF SKRRS GLLKKAHEI SVLCDAEVALI VFS

RI ENKI NRCVTF AKRRNGLLKKAYEL SVLCDAEVALI I FS

. I ANDSARRATLKKRRKGLI KKVEEL STLCDVKACLI VYT

RI ENPTQRCSTFYKRRLGLFKKARELAVLCDALLLLLLFS

RI ENTTNRCVTF SKRRGGLLKKAHELAVL TDTCI GLI I FS

. EKARARLSTNMMRNKGLKKKAGEL SLLCGVLVLLASFS

ENARARLSTHNTRNKGLKKKAGELSLLCGVDVLLASFS

I EEVSSCQNVCFSKRHKGLFKKVVELSI LYGAKI LVL TFS

I I NKI NRCVTFAKRRNGLLKKAYELS.

ENTRARLSTHNTRNKGL KKKAGEL SLLCGVLVLLASFS KI CNATARCQTFSKRRKGLFKKAQELAI LCDAEVGLI I FS RI ENKI NRCVTFAKRRNGLLKKAYELSVLCDAEVALI VFS RI LNI TNRCQTF SKRRNGLLKKAKELAVLCDAEVGLI I FS MKKASELSI LCGVEFAI VAFS LENTSGRCQTYSKRRAGI LKKAKELSI LCLI II VLLMFS TFKKRRAVLI KESHEI SVRCSALVALI VFS RI ENKEARCVCF SKRWAGLI KKATEL SI I CGTEI GI VVFS RI ENNTNRCVTFSKRRNGLI KKAYELSVLCDI LI ALI MFS RI ENKI KRCVTF SKRRS GLLKKAHEI/SVLCDALVALI VFS . I TNDATRRSTLKKRRL GLLKKVNELSI LCNVFACAVI YS . I SNDATRRATLKKRRKGLLKKVKELSI LCDVRACAI I YS . EKSRARVATYNTRNKGLKKKAGEL SLLCGVLVLVASFS . EKSRARVATYNTRNKGLKKKAGELSLLCGVLVLVASFS RI ENATSRCVTF SKRRNGLL KKAFEL SVLCDAEI GLI VFS KI ENPTNRCVTYSKRRAGI MKKASELTVLCLACL SLVMFS KKAKELSI PCGI DVLFASFS ... AKVRI NTYKTRI KGNEKKAKEL SVLCGI DVLFASFS ... AKVRI NTYKTRI KGNEKKAKEL SVLCGI LVLFFSFS RI ENTTNRCVTFCKRRNGLLKKAYELSVLCDAEVSLI VFS RI ENSKSRCVTFSKRRNGLLKKAFELSVLCEAEVGVI I LS

Figure 1. Sequence logo and multiple alignment analysis of the SRF-TF domain: (a) sequence logo of the SRF-TF domain. (b) Multiple alignment analysis of the SRF-TF domain. The different colors of shading indicate the same and conserved amino acid residues, respectively.

To comprehensively investigate the function and regulatory roles of the BsMADSs, we analyzed the various cis-acting elements of the promoter regions. The identified cis-acting elements were classified into five main functional classes: transcription, cell cycle, hormone, abiotic or biotic stress, and development. A total of 103 types of elements were found, most of which were associated with different stress conditions, including hormonal responses such as ABA, GA, MeJA, SA, and auxin, as well as abiotic responses such as wound, low 
temperature, drought, etc. (Figure 2, Supplementary Table S3). We focused on drought inducibility and MeJA-related elements to predict the functions of the BsMADS genes.

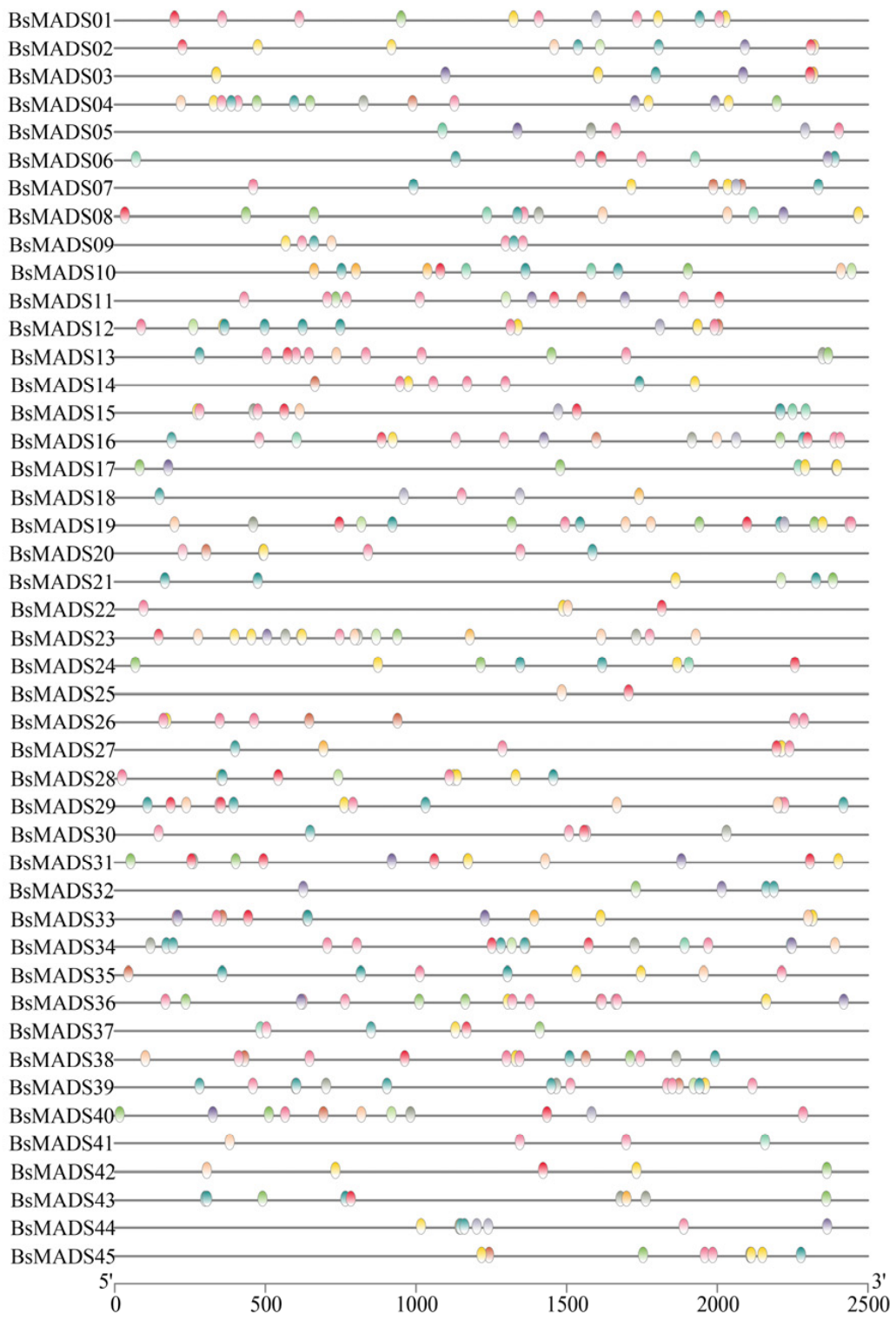

salicylic acid responsive abscisic acid responsive anaerobic induction MeJA-responsive meristem expression endosperm expression auxin responsive circadian control gibberellin-responsive element drought-inducibility auxin-responsive element low-temperature responsive gibberellin-responsive wound-responsive element

Figure 2. Distribution of various cis-acting elements in the promoter regions of B. striata MADS genes (BsMADSs). The cis-elements of the BsMADSs were searched using the online PlantCARE website. Special cis-acting elements were selected (e.g., auxin-responsive elements), and TBtools was used to create the diagrams.

\subsection{Phylogenetic Analysis of the MADS-Box Family between B. striata and Arabidopsis}

To clarify the phylogenetic relationships of the MADS family proteins between $B$. striat $a$ and Arabidopsis, all whole-length amino acid sequences of 45 BsMADS and 146 AtMADS were employed to perform a multiple sequence alignment (MSA) protein analysis. An unrooted phylogenetic tree was developed using the neighbor-joining (NJ) method according to the similarity and topology of sequences, and the 45 BsMADS were distributed into five subgroups: A to E (Figure 3). The results could be highly useful for predicting the various roles of unknown BsMADS according to the functionality confirmed in AtMADS or subgroups in Arabidopsis, which might contribute to the selection of target BsMADS for further functional analysis. 


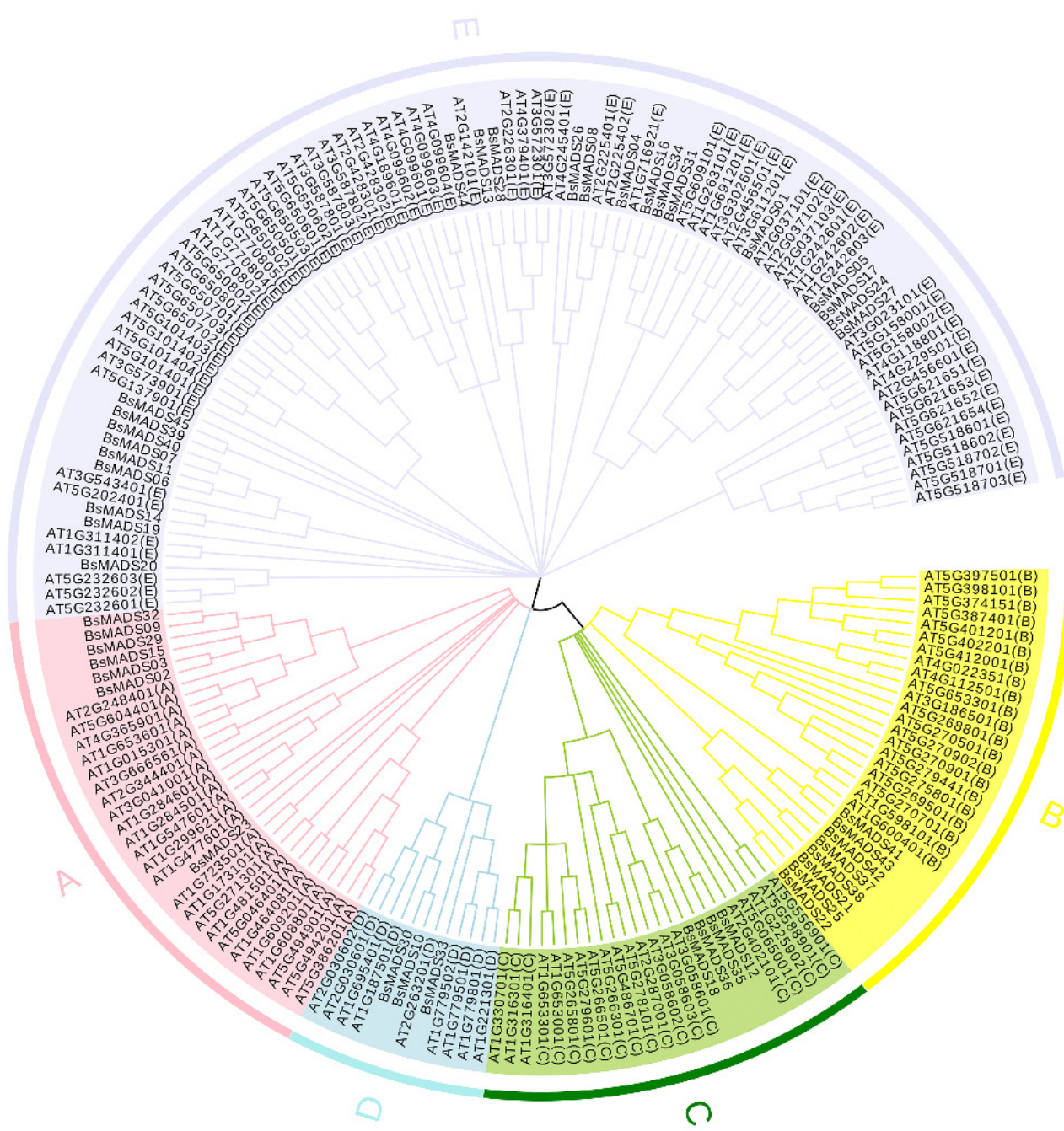

Figure 3. Phylogenetic tree of the MADS-box family proteins in B. striata and Arabidopsis. The unrooted neighbor-joining (NJ) tree was based on the amino acid sequences of AtMADS from B. striata (45) and Arabidopsis (146) using MEGA7 with 1000 bootstrap replicates. The names of the (A-E) groups shown outside the circle indicate different MADS subgroups-A $(\mathrm{M} \alpha), \mathrm{B}(\mathrm{M} \beta), \mathrm{C}(\mathrm{M} \gamma)$, $\mathrm{D}(\mathrm{M} \delta)$, and $\mathrm{E}(\mathrm{MIKC}) ; \mathrm{A}, \mathrm{B}, \mathrm{C}$, and D groups belonged to type I, and E groups belonged to type II.

\subsection{Gene Structure, Motif Composition, and Ka/Ks Analysis of BsMADSs}

To glean insights into the similarities and diversity of gene structures and conserved motifs in BsMADSs, a phylogenetic tree was constructed based on multiple sequence alignments (Figure 4a), which clustered almost identically to the result shown in Figure 3, indicating good consistency. The genomic DNA and CDS sequences were employed to analyze the intron and exon structures of the BsMADSs (Figure 4c). The results of the gene structure analysis showed that the number of introns varied from zero to ten. In the same cluster of the phylogenetic tree, most genes possessed similar exon-intron structures, where among them, $26.7 \%$ of the BsMADSs contained only one exon without introns.

A total of eight conserved motifs were detected in the BsMADSs (Figure $4 \mathrm{~b}$ ), with each motif sequence logo displayed (Figure 4d). Most of the BsMADSs contained Motif-1, Motif-2, and Motif-4. Motif-7 was involved in 19 genes, while Motif-3 existed in 25 genes. Motif- 8 was found in five genes, whereas only three genes contained Motif- 6 . We also found that the MADS genes with close evolutionary relationships shared the same motif compositions, suggesting that the function of MADS proteins is similar. 
$\mathrm{a}$ b

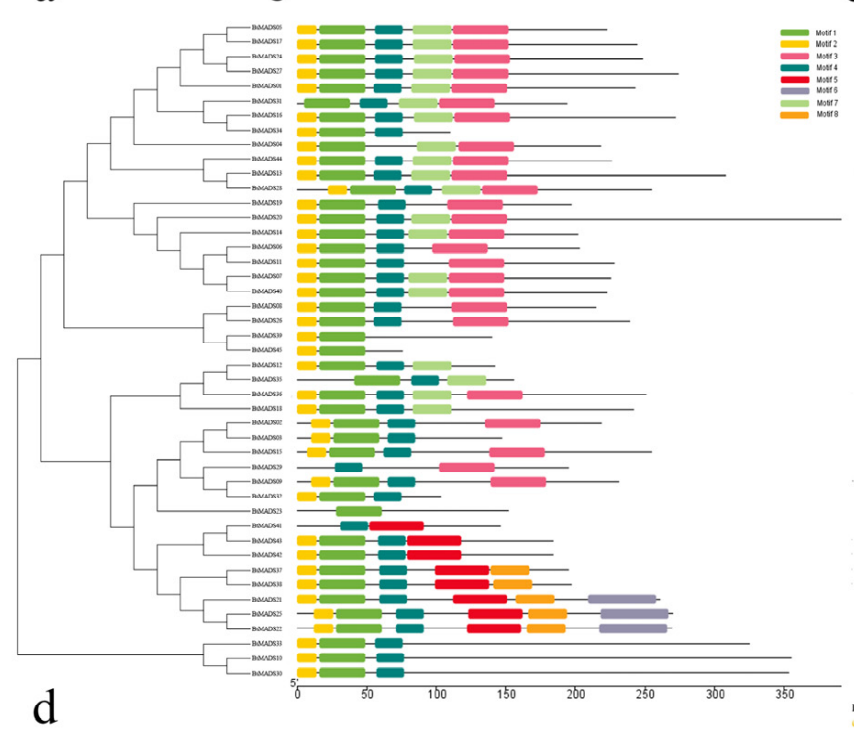

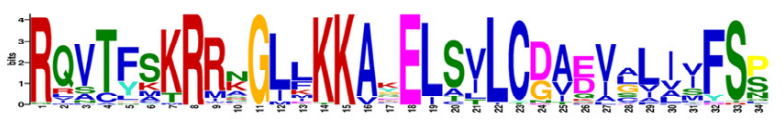

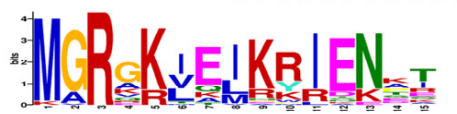

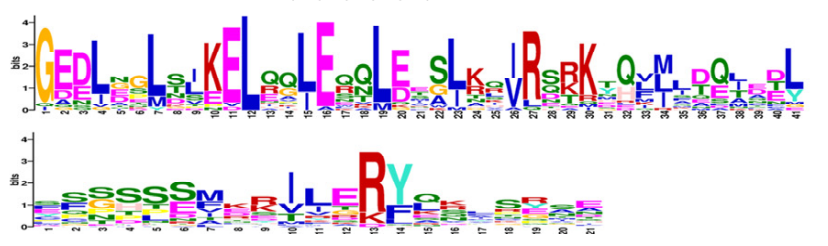

c
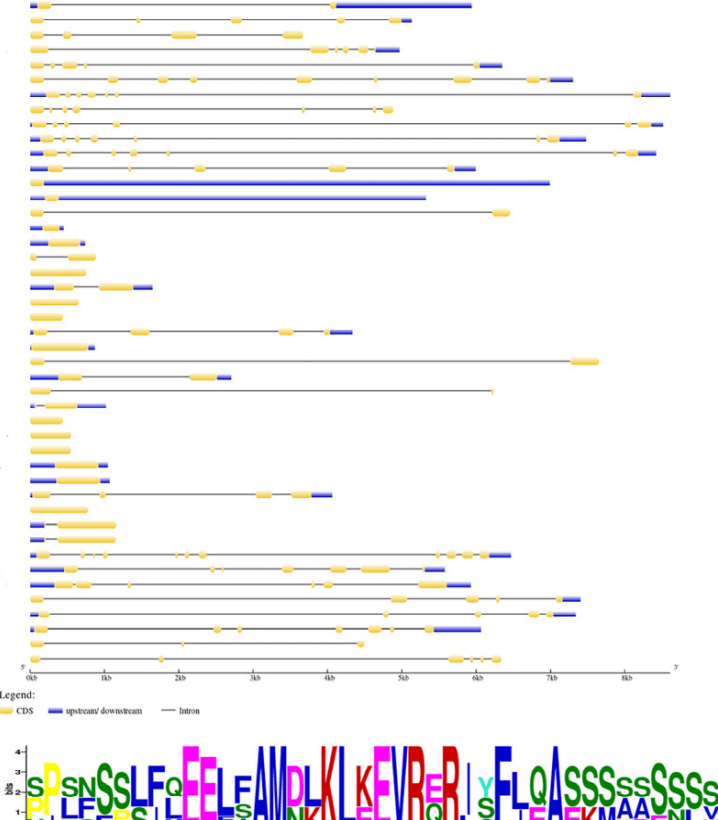

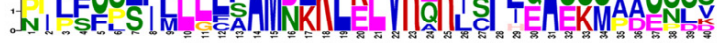

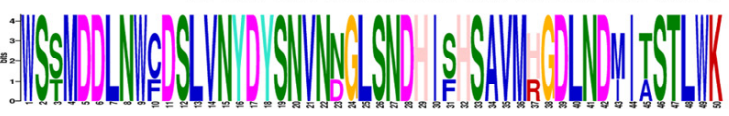

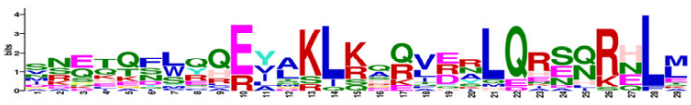

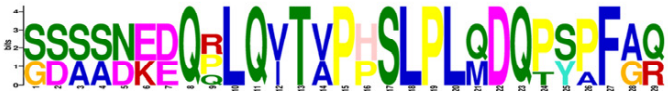

Figure 4. Phylogenetic relationships, conserved motifs, and exon-intron organization of MADS genes: (a) the phylogenetic tree contained 45 MADS proteins (named BsMADS01 to BsMADS45) from B. striata. (b) The motif patterns of the 45 BsMADS proteins. Each motif is shown as boxes of different colors. (c) Exon-intron structures of MADS genes from B. striata. Exon(s) and intron(s) are represented by yellow boxes and black lines, respectively, while the untranslated regions are represented by blue boxes. The number manifested the phases according to the BsMADSs introns. (d) Sequence logos of each motif.

We discovered that there were 14 pairs of homologous genes in the BsMADSs (Figure 4a), which suggested that $\sim 62.2 \%$ BsMADSs were replicated and that the BsMADS family had experienced evolutionary gene expansion. To explore the influence of evolutionary factors on the BsMADS family, the Ka/Ks ratios of 14 BsMADS gene pairs were computed based on the phylogenetic tree (Figure 4). The results showed that the ratios of $92.9 \%$ orthologous gene pairs were no more than 1 , which implied that a strong purifying selective pressure existed in the homologous genes during the course of their evolution (Supplementary Table S4).

\subsection{Synteny Analysis and Chromosomal Distribution of MADS Genes}

Gene duplication events may have given rise to new functionalities that assisted $B$. striata in adapting to changing environments, thus enriching gene family members. Three comparative synteny maps were constructed, including B. striata, A. thaliana, Vanilla fragrans, and Vitis vinifera (Figure 5). A total of 17 MADS genes showed a syntenic relationship with those of $V$. fragrans, followed by $A$. thaliana (4) and $V$. vinifera (10). 


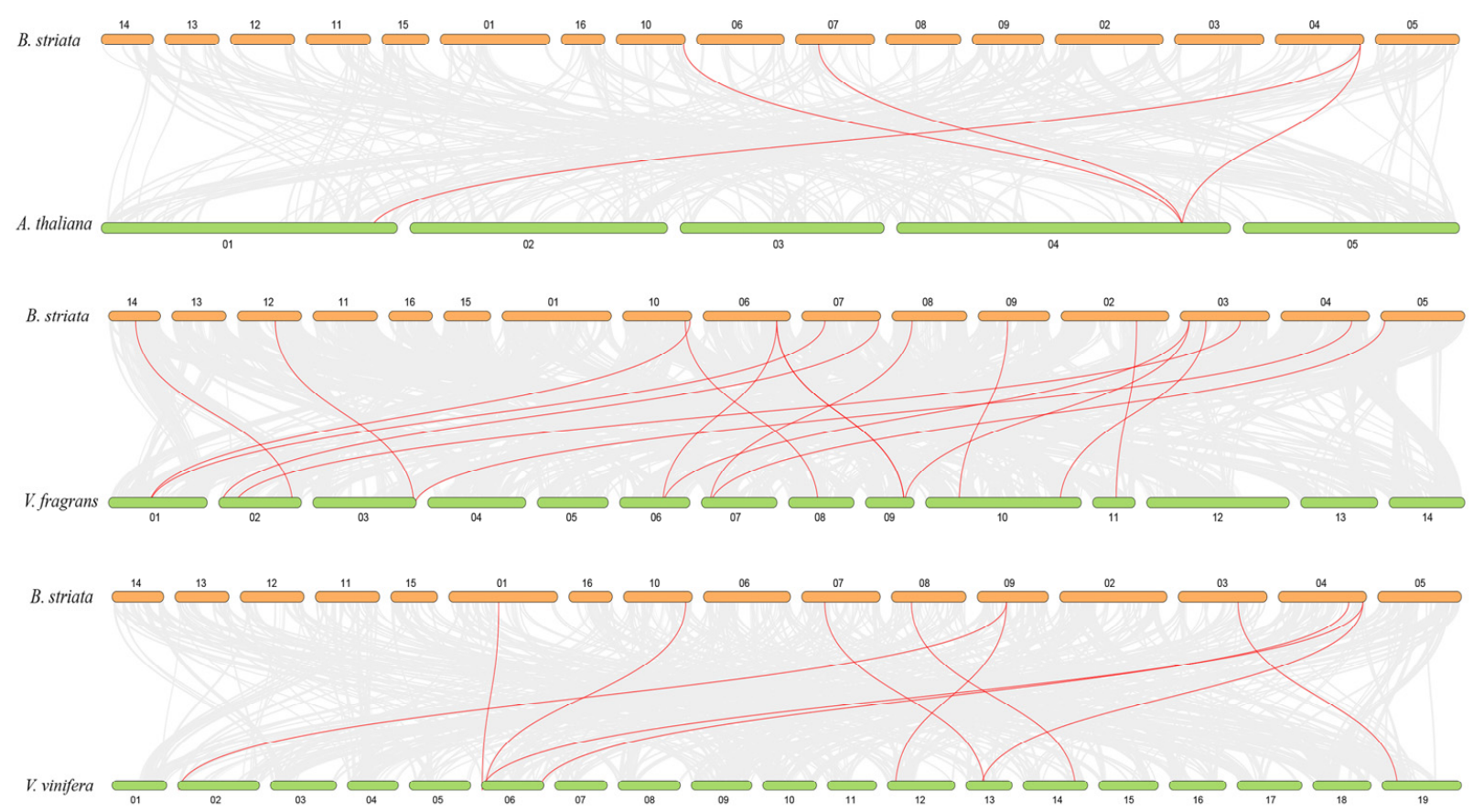

Figure 5. Synteny analysis of MADS genes between B. striata and three other plants (A. thaliana, V. fragrans, and V. vinifera): gray lines indicate the collinear blocks within the $B$. striata genome and the other genomes, while the red lines indicate MADS gene pairs.

To gain insights into the evolution of the 45 B. striata MADS-box genes, we analyzed their genomic distribution and discovered that they were unevenly distributed on chromosomes $01-10$ and 12-14 (except for five members that were found within repeat sequences or unassembled scaffolds) (Figure 6). Chr01 and Chr03 contained six MADS-box genes, while Chr08, Chr09, and Chr14 had only one. The results of genomic distribution proved that some B. striata MADS-box genes of type I or type II were located in the same chromosomal region. A similar previously reported situation regarding the MADS-box genes of Arabidopsis [39] and rice [40] suggested that they were widely distributed across the genomes of the common monocotyledon and dicotyledon ancestors.

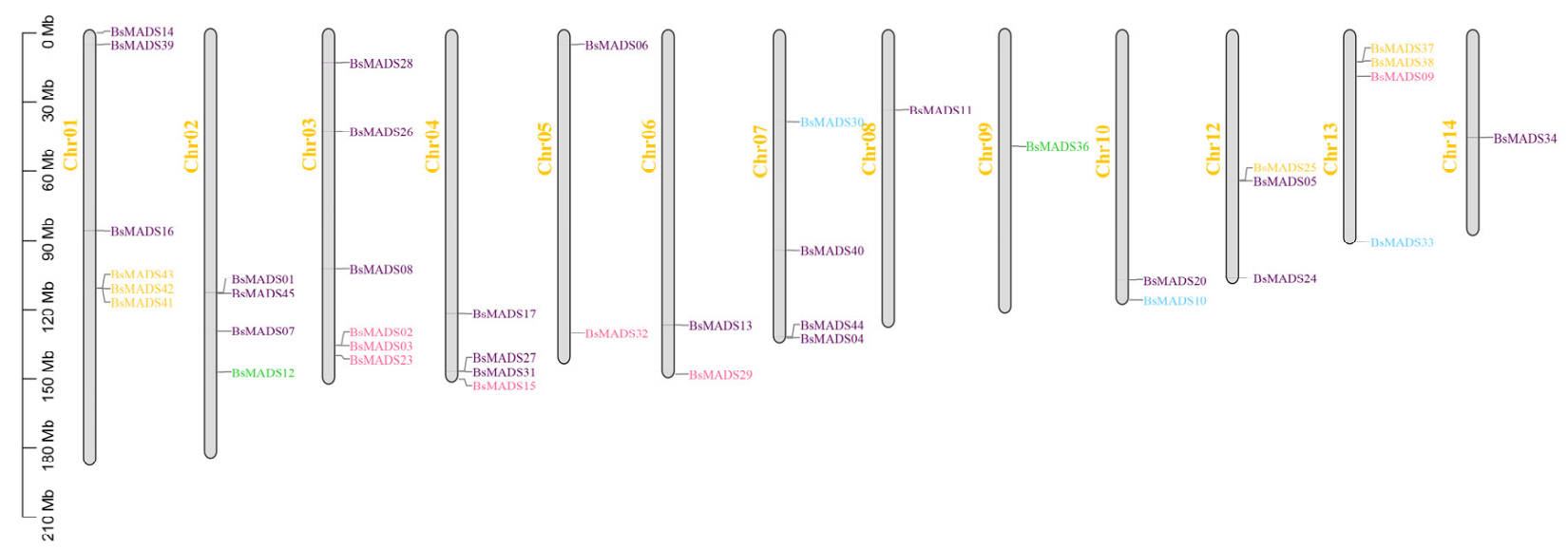

Figure 6. Chromosomal localization of 45 MADS genes in B. striata at the megabase $(\mathrm{Mb})$ scale. The scale of five genes (BsMADS18, BsMADS19, BsMADS21, BsMADS22, and BsMADS35) could not be anchored on a specific chromosome. The pink genes belong to group $A(M \alpha)$, the yellow genes belong to group $B(M \beta)$, the green genes belong to group $C(M \gamma)$, the blue genes belong to group $\mathrm{D}(\mathrm{M} \delta)$, and the purple genes belong to group $\mathrm{E}(\mathrm{MIKC})$. 


\subsection{Expression Profile of BsMADS Genes under Non-Stressed Growth Conditions}

To explore the tissue-specific expression of BsMADSs, we examined their expression profile in roots, stems, leaves, and flowers under non-stressed growth conditions based on quantitative real-time PCR (RT-qPCR) analysis (Figure 7, Supplementary Table S6). The expression levels of diverse $B S M A D S s$ changed significantly between different tissues. From the heatmap, BsMADS01, BsMADS05, BsMADS06, BsMADS07, BsMADS11, BsMADS27, and $B S M A D S 40$ exhibited a higher transcript accumulation in flowers, and they all belonged to group E (MIKC) (Figure 3). This result verified that the MADS-box genes described in the ABCDE model belonged to the MIKC subclass [41,42].
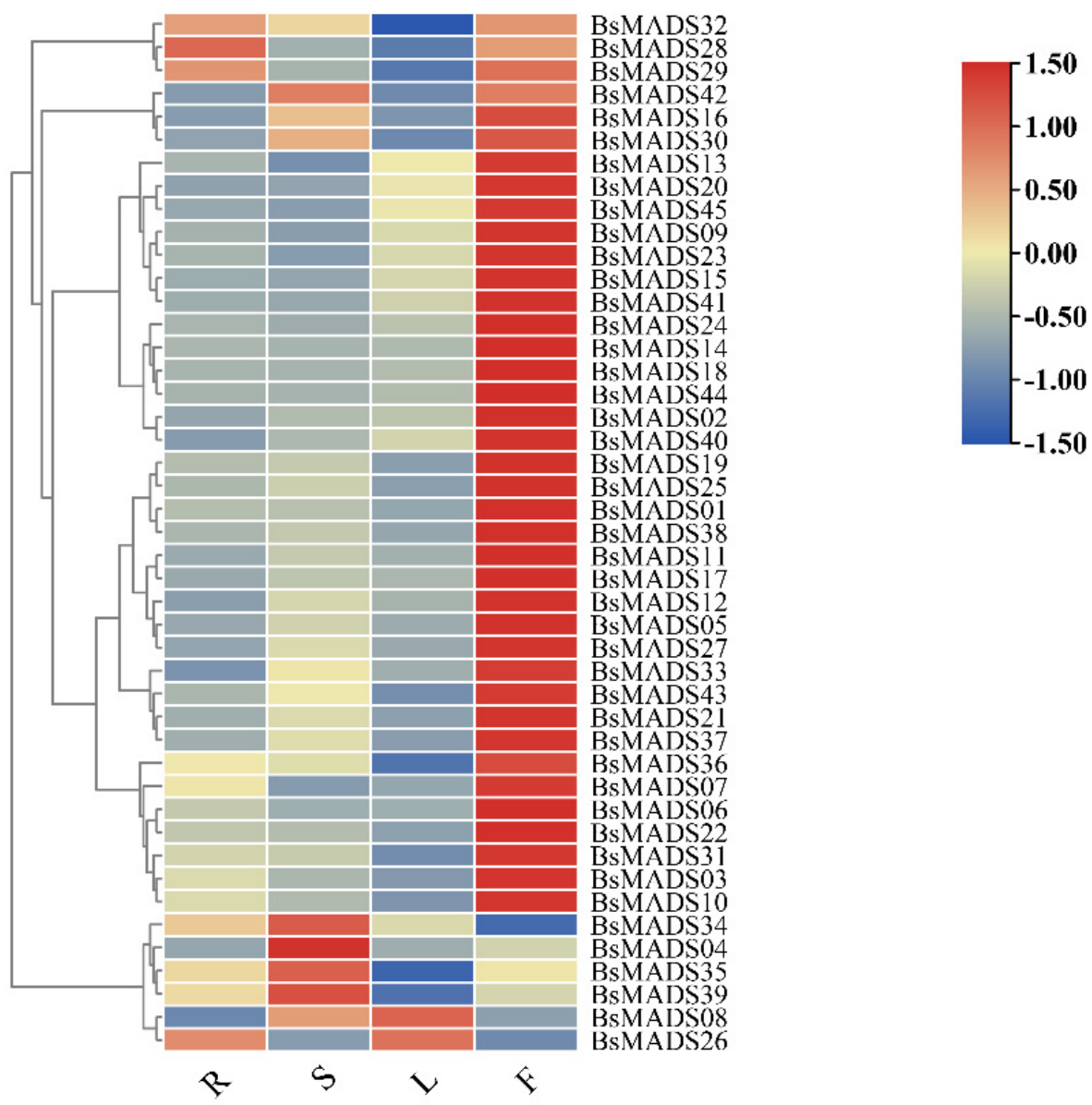

Figure 7. Heatmap showing the expression profile of BsMADSs in four different tissues (root, stem, leaf, and flower) - R (root), S (stem), L (leaf), and F (flower), respectively.

\subsection{Analysis of Expression Patterns under Different Stress Treatments}

Eight BsMADS genes were randomly selected to further analyze their expression level patterns under different abiotic stressors (Figure 8) and hormone treatments (Figure 9) at five time points $(0,1,3,6$, and $12 \mathrm{~h})$. BsMADS03 belonged to group A, BsMADS43 belonged to group $\mathrm{B}, B s M A D S 18$ belonged to group C, BsMADS10 and BsMADS33 belonged to group $\mathrm{D}$, and BsMADS01, BsMADS07, and BsMADS11 belonged to group E. Genetic patterns with significantly different expression levels were detected by RT-qPCR. As shown in Figures 7 and 8, BsMADS33 had robust responses to all treatments, while the expressions of BsMADS01 and BsMADS07 were not obvious under the abiotic treatments, and BsMADS43 was not induced by $\mathrm{NaCl}$. 
a

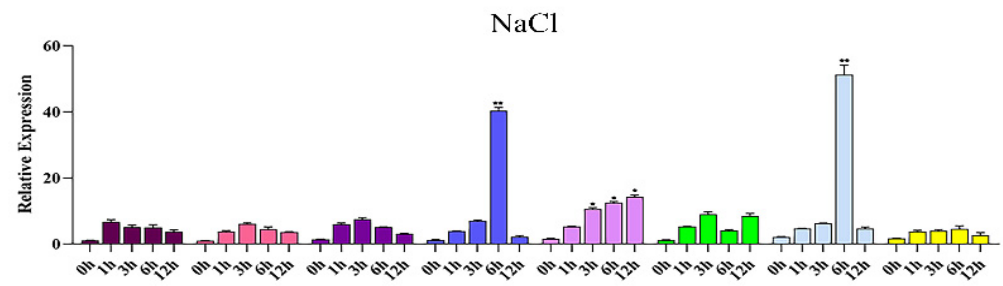

b

$\mathrm{CuSO}_{4}$

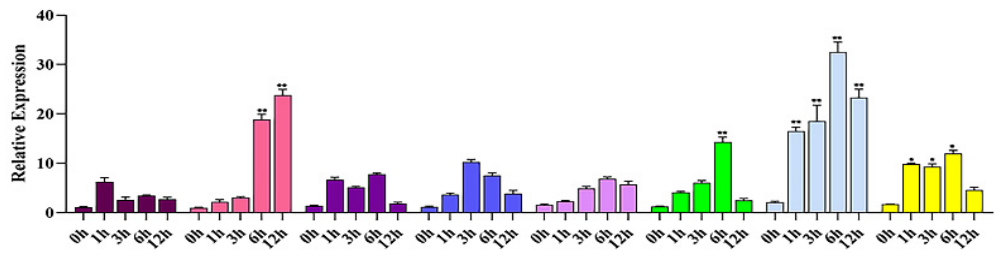

c

$\mathrm{AgNO}_{3}$

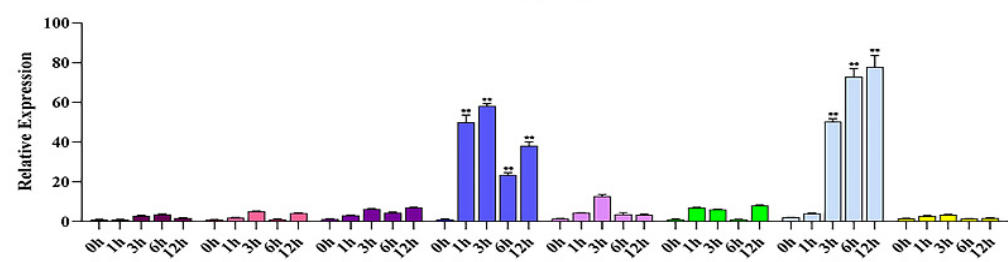

d

MeJA

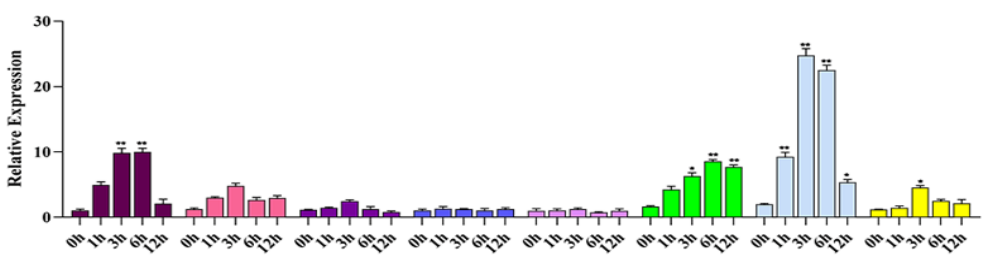

e

ABA

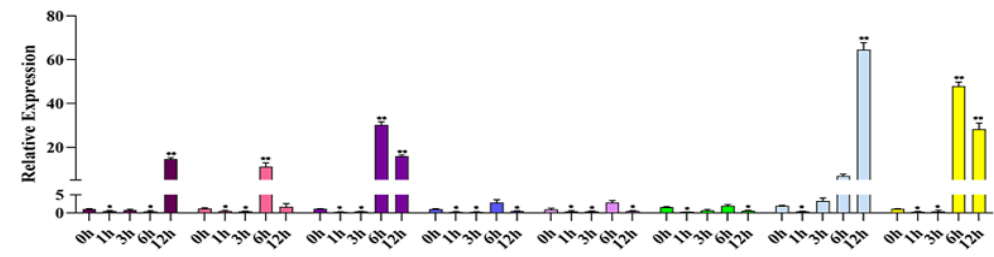

f

SA

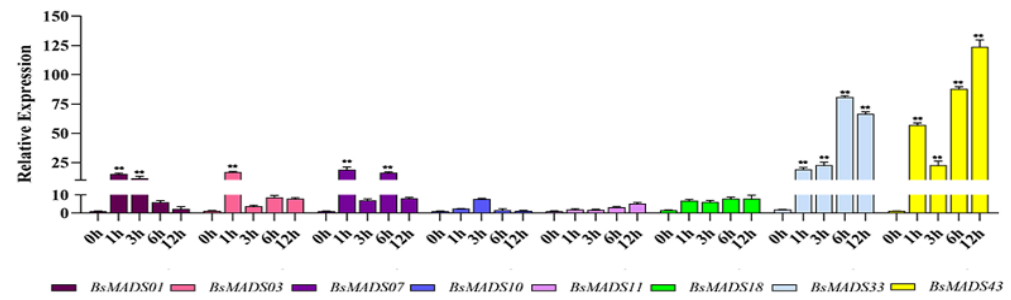

Figure 8. The expression levels of $8 B S M A D S s$ in response to various stress treatments at $0,1,3,6$, and $12 \mathrm{~h}$ : (a) $\mathrm{NaCl}$, (b) $\mathrm{CuSO}_{4}$, (c) $\mathrm{AgNO}_{3}$, (d) MeJA, (e) ABA, and (f) SA. The data were analyzed via the two-way method using GraphPad Prism, version 8. Asterisks $(p<0.05)$ indicate significant differences compared with the control group $\left({ }^{*} p<0.05,{ }^{* *} p<0.01\right)$. Error bars represent standard error for data obtained in three biological replicates. 


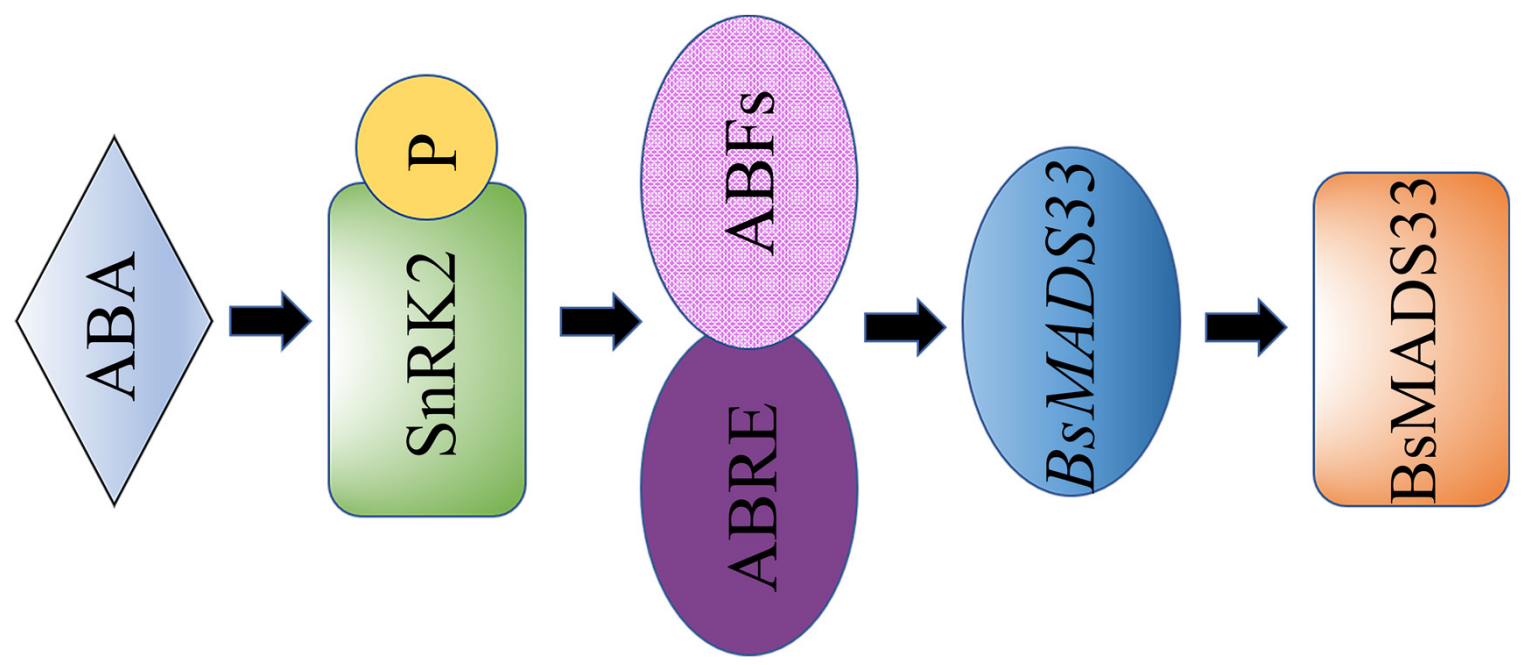

Figure 9. Annotation map of BsMADS33 hypothetical pathway in response to ABA stress.

The expression levels of two MADS genes (BsMADS03 and BsMADS33) dramatically increased under the $\mathrm{CuSO}_{4}$ treatments. Five genes upregulated under $\mathrm{AgNO}_{3}$ stress; among them, BsMADS10 was mostly upregulated $\sim 60$-fold at $1 \mathrm{~h}$, which then decreased, and BsMADS33 continued to increase after being upregulated $\sim 60$-fold at $3 \mathrm{~h}$. BsMADS10 downregulated following the ABA and SA treatments. All genes in the ABA treatment group were initially significantly downregulated and then upregulated, which indicated that the ABA treatment inhibited gene expression within $1 \mathrm{~h}$.

Taking BsMADS33 stimulated by external ABA as an example, we hypothesized that the phosphorylation of SnRK2 protein kinase caused by the ABA signal promotes the binding of $\mathrm{ABRE}$ ( $\mathrm{ABA}$ response elements) to $\mathrm{ABFs}$ (downstream targets) [43], thus regulating the increased gene expression and contributing to the protein products conducive to plant resistance to stress.

\section{Discussion}

The MADS family is one of the largest plant transcription factor families, playing a critical role in plant growth and development and in the regulation of plant responses to both abiotic and biotic stresses $[44,45]$. Although this family has been widely researched for many plants, including Arabidopsis [4,7], rice [34], maize [46,47], Erycina pusilla [36], and Phalaenopsis [37], the identification, expression patterns, and functions of MADSs based on the whole-genome sequence of B. striata have remained poorly understood. Therefore, we conducted a comprehensive and systematic analysis of the MADS-box gene family in B. striata.

For our study, a total of 45 MADS-box genes were identified in B. striata, which was lower than that of both Arabidopsis (146 genes) [19] and rice (75 genes) [1], implying that the MADS family had diminished over the course of evolution. The number of genes varied for different species, which may have been caused by gene duplication (e.g., tandem and segmental duplication) [48,49]; however, members of the RsMADS may not have undergone such a process [50]. It was also revealed that gene function was a major determinant of gene family size, thus further suggesting that natural stressors were the major driving evolutionary forces [51].

To further explore the restrictive conditions during the evolution of the BsMADS family, the $\mathrm{Ka} / \mathrm{Ks}$ ratios of the 28 paralogous BsMADS gene pairs were computed. The smaller the value of $\mathrm{Ka} / \mathrm{Ks}$ between gene pairs, the more severe the selective constraint they evolved. The $\mathrm{Ka} / \mathrm{Ks}$ ratios of most duplicated BsMADS gene pairs were less than 1 , which indicated that the purification selection pressure played a dominant role in the evolutionary process of this family (Supplementary Table S4). The results revealed that the MADS-box gene family was currently being purified under B. striata selection. 
According to the phylogenetic tree between B. striata and Arabidopsis, the BsMADS genes were divided into five subgroups, which also provided a reliable reference for the prediction of functional target BsMADS genes (Figure 3). Some BsMADSs were clustered in the same branch as the known AtMADSs, suggesting the conservation of MADS protein functions between the two species. For example, AGL6 (AGAMOUS-LIKE6, AT2G456501) is involved in the development of bractless flowers in Arabidopsis [7], while the expression level of $A G L 12$ contributes to the regulation and development of root structures (AGAMOUS-LIKE12, AT1G716921) [52], both of which belong to group E (MIKC).

Consequently, BsMADSs in the MIKC subgroups might be regarded as prime candidate genes for the development of plant organs. The results of the sequence alignments revealed characteristic amino acids (e.g., the majority of the BsMADSs contained one critical amino acid residue, which was the 25 th glutamic acid (E)). The secondary structural elements of the SRF-TF domain were found to contain two $\alpha$-helix and three $\beta$-sheets (Figure S1). SRF had been reported to activate transcription by interacting with the B-box [53].

Structural analysis determined that $26.7 \%$ of the BsMADSs contained just one exon (Figure 4). The close BsMADSs had similar structures and conserved motif complements, which also confirmed the impregnable evolutionary conservation. Conserved motifs might serve as potential DNA binding sites to regulate the expression of specific genes $[54,55]$. The transcriptional activities and specificity of DNA combinations depended on unique structures and motifs. Therefore, based on the phylogenetic tree (Figure 3), motif composition analysis (Figure $4 b$ ), and gene structures (Figure 4c), we speculated that the BsMADSs with the same subgroups might have similar functions, which were highly conserved.

The results of the cis-elements analysis suggested the responses of the BsMADS genes to various biotic and abiotic stressors. There have been many studies of plant MADS transcription factors involved in plant growth and development. For example, phytohormone abscisic acid (ABA) was observed to inhibit the expression of FAMADS1a in strawberries and promote fruit ripening [56]. TaMADS2 isolated from wheat was useful for the treatment of wheat-stripe rust interactions [57]. The yields of transgenic rice that overexpressed JCMADS40 were reduced [58]. CpMADS3 in cyclamen had a novel function in flowering [59]. Furthermore, MADS genes participate in multiple abiotic stress responses [60-62].

This suggested that BsMADS genes were likely to be involved in these physiological processes. To further investigate the functionality of MADS-box genes, we analyzed the expression levels of eight randomly selected BsMADSs under different treatments (Figures 8 and 9). BsMADS07, BsMADS10, and BsMADS11 had no significant differences following the MeJA treatment, while the expression of the BsMADS33 gene significantly increased, suggesting that it may regulate the transcription of related genes. Under $\mathrm{Cu}^{2+}$ and $\mathrm{Ag}^{+}$stress conditions, both BsMADS33 and BsMADS10 were upregulated and belonged to group $\mathrm{D}(\mathrm{M} \delta)$.

Therefore, M $\delta$ MADS genes in B. striata may play critical roles in responding to abiotic stresses. According to the phylogeny analysis, the selected BsMADS genes exhibited similar stress-responsive expression patterns to model species within the same clade or subgroup. Among them, BsMADS33 was upregulated under all treatments; thus, we predicted that it could be employed as a candidate gene for later functional research. In brief, the results of our study might provide a credible reference for further research on the functions of type I MADS genes in B. striata.

\section{Materials and Methods}

\subsection{Plant Material and Treatment}

In order to perform a genome-wide analysis of $B$. striata, we planted germplasm resources at the greenhouse in the National Engineering Laboratory for Resource Development of Endangered Chinese Crude Drugs, Northwest China. Seeds $(2 n=2 x=32)$ were collected and sprouted on a seedling bed at $25^{\circ} \mathrm{C}$ under natural lighting $(16 \mathrm{~h}$ light $/ 8 \mathrm{~h}$ dark) at 60-80\% humidity. Two-month-old seedlings were employed for stress-related 
expression profile analysis. For the abiotic stress treatments, the seedlings were treated with $\mathrm{NaCl}(200 \mathrm{mM}), \mathrm{AgNO}_{3}(200 \mathrm{mM})$, and $\mathrm{CuSO}_{4}(200 \mathrm{mM})$ solutions, respectively. The above aseptic seedlings were subjected differently in an MS liquid medium, which contained methyl jasmonate (MeJA, $200 \mu \mathrm{M})$, abscisic acid $(100 \mu \mathrm{M})$, and salicylic acid $(10 \mathrm{mM})$ for the hormonal treatment. The stress samples were collected at $0,1,3,6$, and $12 \mathrm{~h}$ with three biological replicates. Each sample was instantly frozen in liquid nitrogen and stored at $-80^{\circ} \mathrm{C}$ for further RNA isolation.

\subsection{Identification of MADS-Box Gene in B. striata}

A total of 146 previously identified Arabidopsis MADS-domain protein sequences were used to query the $B$. striata database. Further, a BLASTP search of the $B$. striata database was performed using the conserved MADS-domain HMM profile (PF00319) obtained from the Pfam website (Pfam 32.0, http:/ / pfam.xfam.org/, accessed on 9 October 2021) with an e-value (expected value) cut-off set to 0.01 . All potential proteins were confirmed through the SMART service (http:/ / smart.embl-heidelberg.de/, accessed on 9 October 2021). The relative molecular mass and theoretical isoelectric point of all confirmed BsMADS proteins were predicted by ExPASy ProtParam tool (http:/ / expasy.org/, accessed on 9 October 2021).

\subsection{Multiple Alignment and Phylogenetic Analysis}

For multiple alignment analysis, the InterPro program (http:/ / www.ebi.ac.uk/interpro/, accessed on 9 October 2021) was used to acquire the core sequence of the SRF-TF domain, which was further analyzed via the DNAMAN and SMART software programs. The Weblogo (http: / / weblog.berkeley.edu/logo.cgi, accessed on 9 October 2021) online program was employed to reveal the characteristics of the domain.

MADS protein sequences from Arabidopsis were downloaded from the PlantTFDB (http: / / planttfdb.gao-lab.org/, accessed on 9 October 2021). The ClustalX (1.83) program was utilized to perform the alignment of multiple amino acid sequences. The neighborjoining (NJ) method was employed to construct a phylogenetic tree using MEGA v 7.0 with 1000 bootstraps and default parameters of ClusterW.

\subsection{Prediction of Conserved Motifs and Gene Structure Analysis}

The online MEME (http:/ / meme-suite.org/tools/meme, accessed on 9 October 2021) program was utilized to search and detect the protein motifs of 45 BsMADSs with expected e-values of less than $2 \times 10^{-30}$ [63]. The following default parameter setting changed the number of motifs into eight. Next, the result of the XML file obtained from MEME was displayed using TBtools v 0.58 [64]. The exon-intron structures of the BsMADSs were displayed using GSDS (http:/ /gsds.cbi.pku.edu.cn, accessed on 9 October 2021) [65].

\subsection{Cis-Elements and $\mathrm{Ka} / \mathrm{Ks}$ Analysis}

The $2500 \mathrm{bp}$ promoter sequences located upstream of the gene start codon were obtained from the whole-genome sequences of $B$. striata using BioEdit software. The potential cis-elements of BsMADSs were searched in the PlantCARE database [66]. With the purpose of examining whether positive selection existed in the evolution of BsMADS genes, the synonymous substitution rate (Ks) and non-synonymous substitution rate (Ka) values of homologous gene pairs, with their amino acid sequences, were calculated by the online software Clustal Omega (https: / / www.ebi.ac.uk/Tools/msa/clustalo/, accessed on 9 October 2021) and PAL2NAL (http://www.bork.embl.de/pal2nal/, accessed on 9 October 2021) [67].

\subsection{RT-qPCR Analysis}

Four different tissue (root, stem, leaf, and flower) samples of two-year-old B. striata were individually collected during its flowering development stage. These samples were used to conduct RT-qPCR to detect the tissue-specific BsMADSs expression patterns. The 
PCR conditions were set at $95^{\circ} \mathrm{C}$ for $30 \mathrm{~s}, 95{ }^{\circ} \mathrm{C}$ for $5 \mathrm{~s}$, and $60{ }^{\circ} \mathrm{C}$ for $30 \mathrm{~s}$ with 45 cycles. Each reaction had three biological and technical replicates, which used 30 -fold diluted cDNA as a template. The $2^{-\triangle \triangle \mathrm{CT}}$ method was employed to calculate the corresponding expression values of the BsMADSs. According to our laboratory studies, we selected $B s G A P D H$ as the internal reference gene in this work, with the primer sequences listed in Supplementary Table S5.

\section{Conclusions}

In summary, we identified $45 B s M A D S$ genes in B. striata, and the phylogenetic relationships, gene structures, conserved motifs, cis-acting elements, and expression profiles of this family were comprehensively analyzed for the first time. This revealed that BsMADS had a significant role in response to $\mathrm{ABA}, \mathrm{SA}, \mathrm{MeJA}, \mathrm{NaCl}, \mathrm{CuSO}_{4}$, and $\mathrm{AgNO}_{3}$ stressors. Based on the analysis of the phylogenetic tree and expression patterns, we predicted and verified the potential functions of the BSMADSs in our study, which provided a credible reference for further exploring the regulatory mechanisms and stress resistance in the development of $B$. striata.

Supplementary Materials: The following are available online at https://www.mdpi.com/article/10 .3390/plants10102184/s1: Table S1, List of the 45 BsMADS genes identified in this study; Table S2, Physicochemical property; Table S3, The promoter cis-elements analysis of the MADS genes in B. striata; Table S4, Ka/Ks analysis for the duplicated BsMADS paralogs.; Table S5, Analysis and distribution of conserved motifs of MADS proteins in B. striata; Table S6, Primers of sequences; and Figure S1. SRF-TF.

Author Contributions: J.-F.N. and Z.-Z.W. conceived and designed the experiments; Z.-Y.M., Q.Z. (Qian Zhao) and C.L. performed the experiments; Q.Z. (Qian Zhang), S.L. and L.L. analyzed the data; Z.-Y.M. drafted the manuscript, and J.-F.N., Z.-Z.W. and S.-Q.W. revised it. All authors have discussed and commented on the manuscript. All authors have read and agreed to the published version of the manuscript.

Funding: This work was supported by the National Natural Science Foundation of China [grant numbers 82104323 and 32170378]; National Key Technologies R \& D Program for Modernization of Traditional Chinese Medicine [grant numbers 2017YFC1701300 and 2017YFC1700706]; Xi' an Science and Technology Project (20NYYF0057); Fundamental Research Funds for the Central Universities [grant numbers GK202103065 and GK201806006]; Shaanxi Provincial Key R \& D Program (2021SF-383, 2020LSFP2-21 and 2018FP2-26); Research Project on Postgraduate Education and Teaching Reform of Shaanxi Normal University (GERP-20-41); and Youth Innovation Team Construction Scientific Research Project of Shaanxi Education Department(21JP027).

Data Availability Statement: The data used to support the findings of this study are available from the corresponding author upon request.

Conflicts of Interest: All authors declare that there are no conflict of interest regarding the publication of this paper.

\section{References}

1. Arora, R.; Agarwal, P.; Ray, S.; Singh, A.K.; Singh, V.P.; Tyagi, A.K.; Kapoor, S. MADS-box gene family in rice: Genome-wide identification, organization and expression profiling during reproductive development and stress. BMC Genom. 2007, 8, 242. [CrossRef] [PubMed]

2. Tang, W.; Tu, Y.Y.; Cheng, X.J.; Zhang, L.L.; Meng, H.L.; Zhao, X.; Zhang, W.; He, B.; Amato, A. Genome-wide identification and expression profile of the MADS-box gene family in Erigeron breviscapus. PLoS ONE 2019, 14, e0226599. [CrossRef]

3. Shchennikova, A.V.; Shulga, O.A.; Skryabin, K.G. Diversification of the homeotic AP3 clade MADS-box genes in asteraceae species Chrysanthemum morifolium L. and Helianthus annuus L. Dokl. Biochem. Biophys. 2018, 483, 348-354. [CrossRef] [PubMed]

4. Sun, C.H.; Yu, J.Q.; Wen, L.Z.; Guo, Y.H.; Sun, X.; Hao, Y.J.; Hu, D.G.; Zheng, C.S. Chrysanthemum MADS-box transcription factor CmANR1 modulates lateral root development via homo-/heterodimerization to influence auxin accumulation in Arabidopsis. Plant Sci. 2017, 266, 27-36. [CrossRef] [PubMed]

5. Hu, L.F.; Liu, S.; Somers, D.J. Genome-wide analysis of the MADS-box gene family in cucumber. Genome 2012, 55, 245-256. [CrossRef] 
6. Wu, Y.W.; Ke, Y.Z.; Wen, J.; Guo, P.C.; Ran, F.; Wang, M.M.; Liu, M.M.; Li, P.F.; Li, J.N.; Du, H.; et al. Evolution and expression analyses of the MADS-box gene family in Brassica napus. PLoS ONE 2018, 13, e0200762. [CrossRef]

7. Koo, S.C.; Bracko, O.; Mi, S.P.; Schwab, R.; Chun, H.J.; Park, K.M.; Seo, J.S.; Grbic, V.; Balasubramanian, S.; Schmid, M.; et al. Control of lateral organ development and flowering time by the Arabidopsis thaliana MADS-box Gene AGAMOUS-LIKE6. Plant J. 2010, 62, 807-816. [CrossRef]

8. Alvarez-Buylla, E.R.; Pelaz, S.; Liljegren, S.J.; Gold, S.E.; Burgeff, C.; Ditta, G.S.; Ribas de Pouplana, L.; Martinez-Castilla, L.; Yanofsky, M.F. An ancestral MADS-box gene duplication occurred before the divergence of plants and animals. Proc. Natl. Acad. Sci. USA 2000, 97, 5328-5333. [CrossRef] [PubMed]

9. Damveld, R.A.; Arentshorst, M.; Franken, A.; Vankuyk, P.A.; Klis, F.M.; Ram, A. The Aspergillus niger MADS-box transcription factor RlmA is required for cell wall reinforcement in response to cell wall stress. Mol. Microbiol. 2010, 58, 305-319. [CrossRef]

10. Pelaz, S.; Ditta, G.S.; Baumann, E.; Wisman, E.; Yanofsky, M.F. B and C floral organ identity functions require SEPALLATA MADS-box genes. Nature 2000, 405, 200-203. [CrossRef]

11. Honma, T.; Goto, K. Complexes of MADS-box proteins are sufficient to convert leaves into floral organs. Nature 2001, 409, 525-529. [CrossRef] [PubMed]

12. Henschel, K.; Kofuji, R.; Hasebe, M.; Saedler, H.; Münster, T.; Theissen, G. Two ancient classes of MIKC-type MADS-box genes are present in the moss Physcomitrella patens. Mol. Biol. Evol. 2002, 19, 801-814. [CrossRef] [PubMed]

13. Nilsson, L.; Carlsbecker, A.; Sundås-Larsson, A.; Vahala, T. APETALA2 like genes from Picea abies show functional similarities to their Arabidopsis homologues. Planta 2007, 225, 589-602. [CrossRef] [PubMed]

14. Passmore, S.; Maine, G.T.; Elble, R.; Christ, C.; Tye, B.K. Saccharomyces cerevisiae protein involved in plasmid maintenance is necessary for mating of MAT $\alpha$ cells. J. Mol. Biol. 1988, 204, 593-606. [CrossRef]

15. Yanofsky, M.F.; Ma, H.; Bowman, J.L.; Drews, G.N.; Feldmann, K.A.; Meyerowitz, E.M. The protein encoded by the Arabidopsis homeotic gene agamous resembles transcription factors. Nature 1990, 346, 35-39. [CrossRef]

16. Sommer, H.; Beltrán, J.P.; Huijser, P.; Pape, H.; Schwarz-Sommer, Z. Deficiens, a homeotic gene involved in the control of flower morphogenesis in Antirrhinum majus: The protein shows homology to transcription factors. Embo J. 1990, 9, 605-613. [CrossRef]

17. Norman, C.; Runswick, M.; Pollock, R.; Treisman, R. Isolation and properties of cDNA clones encoding SRF, a transcription factor that binds to the $c$-fos serum response element. Cell 1988, 55, 989-1003. [CrossRef]

18. Bodt, S.D.; Raes, J.; Peer, Y.; TheißEn, G. And then there were many: MADS goes genomic. Trends Plant Sci. $2003,8,475-483$. [CrossRef]

19. Parenicova, L.; de Folter, S.; Kieffer, M.; Horner, D.S.; Favalli, C.; Busscher, J.; Cook, H.E.; Ingram, R.M.; Kater, M.M.; Davies, B.; et al. Molecular and phylogenetic analyses of the complete MADS-box transcription factor family in Arabidopsis: New openings to the MADS world. Plant Cell. 2003, 15, 1538-1551. [CrossRef]

20. Becker, A.; Thei $\beta E n$, G. The major clades of MADS-box genes and their role in the development and evolution of flowering plants. Mol. Phylogenet Evol. 2003, 29, 464-489. [CrossRef]

21. Yang, Y.; Jack, T. Defining subdomains of the K domain important for protei-protein interactions of plant MADS proteins. Plant Mol. Biol. 2004, 55, 45-59. [CrossRef]

22. Ng, M.; Yanofsky, M.F. Function and evolution of the plant MADS-box gene family. Nat. Rev. Genet. 2001, 2, 186-195. [CrossRef]

23. Hou, X.J.; Liu, S.R.; Khan, M.R.G. Genome-wide identification, classification, expression profiling, and SSR marker development of the MADS-box gene family in citrus. Plant Mol. Biol. Rep. 2014, 32, 28-41. [CrossRef]

24. Lu, S.J.; Wei, H.; Wang, Y.; Wang, H.M.; Yang, R.F.; Zhang, X.B.; Tu, J.M. Overexpression of a transcription factor OsMADS15 modifies plant architecture and flowering time in rice (Oryza sativa L.). Plant Mol. Biol. Rep. 2012, 30, 1461-1469. [CrossRef]

25. Xu, D.; Pan, Y.; Chen, J. Chemical constituents, pharmacologic properties, and clinical applications of Bletilla striata. Front Pharmacol. 2019, 10, 1168. [CrossRef]

26. Hossain, M.M. Therapeutic orchids: Traditional uses and recent advances-an overview. Fitoterapia 2011, 82, 102-140. [CrossRef]

27. Kumar, M.; Kherawat, B.S.; Dey, P.; Saha, D.; Singh, A.; Bhatia, S.K.; Ghodake, G.S.; Kadam, A.A.; Kim, H.; Manorama; et al. Genome-Wide Identification and Characterization of PIN-FORMED (PIN) Gene Family Reveals Role in Developmental and Various Stress Conditions in Triticum aestivum L. Int. J. Mol. Sci. 2021, 22, 7396. [CrossRef]

28. Kesawat, M.S.; Kherawat, B.S.; Singh, A.; Dey, P.; Kabi, M.; Debnath, D.; Saha, D.; Khandual, A.; Rout, S.; Manorama; et al. Genome-Wide Identification and Characterization of the Brassinazole-resistant (BZR) Gene Family and Its Expression in the Various Developmental Stage and Stress Conditions in Wheat (Triticum aestivum L.). Int. J. Mol. Sci. 2021, 22, 8743. [CrossRef] [PubMed]

29. Tong, T.; Fang, Y.; Zhang, Z.; Zheng, J.; Zhang, X.; Li, J.; Niu, C.; Xue, D.; Zhang, X. Genome-wide identifcation and expression pattern analysis of the KCS gene family in barley. Plant Growth Regul. 2020, 93, 89-103. [CrossRef]

30. Baruah, P.M.; Krishnatreya, D.B.; Bordoloi, K.S.; Gill, S.S.; Agarwala, N. Genome wide identification and characterization of abiotic stress responsive lncRNAs in Capsicum annuum. Plant Physiol. Bioch. 2021, 162, 221-236. [CrossRef]

31. Jiang, M.; Chen, H.; Liu, J.; Du, Q.; Lu, S.; Liu, C. Genome-wide identification and functional characterization of natural antisense transcripts in Salvia miltiorrhiza. Sci. Rep. 2021, 11, 4769. [CrossRef]

32. Wang, M.; Chen, B.; Zhou, W.; Xie, L.; Wang, L.; Zhang, Y.; Zhang, Q. Genome-wide identification and expression analysis of the AT-hook Motif Nuclear Localized gene family in soybean. BMC Genom. 2021, 22, 361. 
33. Burgeff, C.; Liljegren, S.J.; Tapia-López, R.; Yanofsky, M.F.; Alvarez-Buylla, E.R. MADS-box gene expression in lateral primordia, meristems and differentiated tissues of Arabidopsis thaliana roots. Planta 2002, 214, 365-372. [CrossRef] [PubMed]

34. Lopez-Dee, Z.P.; Wittich, P.; PE', M.E.; Rigola, D.; Buono, I.D.; Gorla, M.S.; Kater, M.M.; Colombo, L. OsMADS13, a novel rice MADS-box gene expressed during ovule development. Dev. Genet. 1999, 25, 237-244. [CrossRef]

35. Prasad, K.; Parameswaran, S.; Vijayraghavan, U. OsMADS1, a rice MADS-box factor, controls differentiation of specific cell types in the lemma and palea and is an early-acting regulator of inner floral organs. Plant J. 2010, 43, 915-928. [CrossRef]

36. Lin, C.S.; Hsu, C.T.; Liao, D.C.; Chang, W.J.; Chou, M.L.; Huang, Y.T.; Chen, J.W.; Ko, S.S.; Chan, M.T.; Shih, M.C. Transcriptomewide analysis of the MADS-box gene family in the orchid Erycina pusilla. Plant Biotechnol. J. 2016, 14, 284-298. [CrossRef]

37. Guo, B.; Zhang, T.; Shi, J.L.; Chen, D.H.; Shen, D.L.; Feng, M. Cloning and characterization of a novel PI-like MADS-box gene in Phalaenopsis orchid. J. Biochem. Mol. Biol. 2008, 40, 845-852.

38. Riechmann, J.L.; Meyerowitz, E.M. MADS domain proteins in plant development. Bio Chem. 1997, 378, $1079-1101$.

39. Yoshida, T.; Kawabe, A. Importance of gene duplication in the evolution of genomic imprinting revealed by molecular evolutionary analysis of the type I MADS-box gene family in Arabidopsis species. PLoS ONE 2013, 8, e73588. [CrossRef]

40. Theien, G.; Kim, J.T.; Saedler, H. Classification and phylogeny of the MADS-box multigene family suggest defined roles of MADS-box gene subfamilies in the morphological evolution of eukaryotes. J. Mol. Evol. 1996, 43, 484-516. [CrossRef]

41. Lydia, G.; Günter, T. Phylogenomics of MADS-box genes in plants-two opposing life styles in one gene family. Biology 2013, 2, 1150-1164.

42. Tian, Y.; Dong, Q.L.; Ji, Z.R.; Chi, F.M.; Cong, P.H.; Zhou, Z.S. Genome-wide identification and analysis of the MADS-box gene family in apple. Gene 2015, 555, 277-290. [CrossRef] [PubMed]

43. Hwang, K.; Susila, H.; Nasim, Z.; Jung, J.; Ahn, J.H. Arabidopsis ABF3 and ABF4 Transcription Factors Act with the NF-YC Complex to Regulate SOC1 Expression and Mediate Drought-Accelerated Flowering. Mol. Plant. 2019, 12, 489-505. [CrossRef]

44. Dong, T.T.; Hu, Z.L.; Deng, L.; Wang, Y.; Zhu, M.K.; Zhang, J.L.; Chen, G.P. A tomato MADS-box transcription factor, S1MADS1, acts as a negative regulator of fruit ripening. Plant Physiol. 2013, 163, 1026-1036. [CrossRef] [PubMed]

45. Kobayashi, K.; Maekawa, M.; Miyao, A.; Hirochika, H.; Kyozuka, J. PANICLE PHYTOMER2 (PAP2), encoding a SEPALLATA subfamily MADS-box protein, positively controls spikelet meristem identity in rice. Plant Cell Physiol. 2009, 51, 47-57. [CrossRef] [PubMed]

46. Heuer, S. The maize MADS box gene ZmMADS3 affects node number and spikelet development and is co-expressed with ZmMADS1 during flower development, in egg cells, and early embryogenesis. Plant Physiol. 2001, 127, 33-45. [CrossRef]

47. Zhao, Y.; Li, X.Y.; Chen, W.J.; Peng, X.J.; Xiao, C.; Zhu, S.W.; Cheng, B.J. Whole-genome survey and characterization of MADS-box gene family in maize and sorghum. Plant Cell Tiss Org. 2011, 105, 159-173. [CrossRef]

48. Li, K.Y.; Anamika, S.; Crooks, D.R.; Dai, X.M.; Cong, Z.Z.; Liang, P.; Dung, H.; Rouault, T.A.; Tracey, A.; Deb, S. Expression of human frataxin is regulated by transcription factors SRF and TFAP2. PLoS ONE 2010, 5, e12286. [CrossRef]

49. Lundon, D.J.; Boland, A.; Prencipe, M.; Hurley, G.; O’Neill, A.; Kay, E.; Aherne, S.T.; Doolan, P.; Madden, S.F.; Clynes, M.; et al. The prognostic utility of the transcription factor SRF in docetaxel-resistant prostate cancer: In-vitro discovery and in-vivo validation. BMC Cancer 2017, 17, 163. [CrossRef]

50. Li, C.; Wang, Y.; Liang, X.; Nie, S.S.; Chen, Y.L.; Liang, D.Y.; Sun, X.C.; Karanja, B.K.; Luo, X.B.; Liu, L.W. Genome-wide characterization of the MADS-box gene family in radish (Raphanus sativus L.) and assessment of its roles in flowering and floral organogenesis. Front. Plant Sci. 2016, 7, 1390. [CrossRef]

51. Prachumwat, A.; Li, W.H. Gene number expansion and contraction in vertebrate genomes with respect to invertebrate genomes. Genome Res. 2008, 18, 221-232. [CrossRef] [PubMed]

52. Montiel, G.; Gaudet, M.; Laurans, F.; Rozenberg, P.; Simom, M.; Gantet, P.; Jay-Allemand, C.; Breton, C. Overexpression of MADS-box gene AGAMOUS-LIKE 12 activates root development in Juglans sp. and Arabidopsis thaliana. Plants 2020, 9, 444. [CrossRef]

53. Brown, L.A.; Yang, S.H.; Hair, A.; Galanis, A.; Sharrocks, A.D. Molecular characterization of a zebrafish TCF ETS-domain transcription factor. Front. Plant Sci. 2000, 18, 7985-7993. [CrossRef]

54. Song, X.M.; Liu, T.K.; Duan, W.K.; Ma, Q.H.; Ren, J.; Wang, Z.; Li, Y.; Hou, X.L. Genome-wide analysis of the GRAS gene family in Chinese cabbage (Brassica rapa ssp. pekinensis). Genomics 2014, 103, 135-146. [CrossRef]

55. Duan, W.K.; Song, X.M.; Liu, T.K.; Huang, Z.N.; Ren, J.; Hou, X.L.; Ying, L. Genome-wide analysis of the MADS-box gene family in Brassica rapa (Chinese cabbage). Mol. Genet Genom. 2015, 290, 239-255. [CrossRef]

56. Lu, W.J.; Chen, J.X.; Ren, X.C.; Yuan, J.J.; Han, X.Y.; Mao, L.C.; Ying, T.J.; Luo, Z.S. One novel strawberry MADS-box transcription factor FaMADS1a acts as a negative regulator in fruit ripening. Sci. Hortic.-Amsterdam 2018, 227, 124-131. [CrossRef]

57. Guo, J.; Shi, X.X.; Zhang, J.S.; Duan, Y.H.; Bai, P.F.; Guan, X.N.; Kang, Z.S. A type I MADS-box gene is differentially expressed in wheat in response to infection by the stripe rust fungus. Biol. Plantarum. 2013, 57, 540-546. [CrossRef]

58. Tang, Y.H.; Wang, J.; Bao, X.X.; Wu, Q.; Yang, T.W.; Li, H.; Wang, W.X.; Zhang, Y.Z.; Bai, N.N.; Guan, Y.X.; et al. Genome-wide analysis of Jatropha curcas MADS-box gene family and functional characterization of the JcMADS40 gene in transgenic rice. BMC Genom. 2020, 21, 325. [CrossRef]

59. Tanaka, Y.; Yamamura, T.; Terakawa, T. Identification and expression analysis of the Cyclamen persicum MADS-box gene family. Plant Biotechnol. 2011, 28, 167-172. [CrossRef] 
60. Jia, J.T.; Zhao, P.C.; Cheng, L.Q.; Yuan, G.X.; Yang, W.G.; Liu, S.; Chen, S.Y.; Qi, D.M.; Liu, G.S.; Li, X.X. MADS-box family genes in sheepgrass and their involvement in abiotic stress responses. BMC Plant Bio. 2018, 18, 42. [CrossRef] [PubMed]

61. Wei, B.; Zhang, R.Z.; Guo, J.J.; Liu, D.M.; Li, A.L.; Fan, R.C.; Zhang, X.Q. Genome-wide analysis of the MADS-box gene family in Brachypodium distachyon. PLoS ONE 2014, 9, e84781. [CrossRef] [PubMed]

62. Li, F.F.; Chen, X.Y.; Zhou, S.G.; Xie, Q.L.; Wang, Y.S.; Xiang, X.X.; Hu, Z.L.; Chen, G.P. Overexpression of SIMBP22 in tomato affects plant growth and enhances tolerance to drought stress. Plant Sci. 2020, 301, 110672. [CrossRef] [PubMed]

63. Bailey, T.L.; Nadya, W.; Chris, M.; Li, W.W. MEME: Discovering and analyzing DNA and protein sequence motifs. Nucleic Acids Res. 2006, 34, W369-W373. [CrossRef] [PubMed]

64. Chen, C.; Chen, H.; Zhang, Y.; Thomas, H.R.; Xia, R. TBtools: An Integrative Toolkit Developed for Interactive Analyses of Big Biological Data. Mol. Plant. 2020, 13, 1194-1202. [CrossRef] [PubMed]

65. Hu, B.; Jin, J.; Guo, A.Y.; Zhang, H.; Luo, J.; Gao, G. GSDS 2.0: An upgraded gene feature visualization server. Bioinformatics 2015, 31, 1296-1297. [CrossRef]

66. Magali, L.; Patrice, D.; Gert, T.; Marchal, K.; Moreau, Y.; Van de Peer, Y.; Rouzé, P.; Rombauts, S. PlantCARE, a database of plant cis-acting regulatory elements and a portal to tools for in silico analysis of promoter sequences. Nucleic Acids Res. 2002, 30, 325-327.

67. Hurst, L.D. The Ka/Ks ratio: Diagnosing the form of sequence evolution. Trends Genet. 2002, 18, 486-487. [CrossRef] 